The E-Health Experience in Australia: The National Health Services Directory (NHSD) and National Healthmap

Laurie Hawkins

Across the world as countries struggle to balance rising consumer expectations, escalating demands on health systems, an ageing population, rising rates of chronic disease, and increasing costs, now is the time to consider looking at new concepts to transform how health and social care is delivered. In Australia, one new concept adopted nationally is the National Health Services Directory (NHSD) ${ }^{1}$ - a repository of health and human services, which combines operational data for Health/Human Services and Provider data for transactional information to provide continuity of care for health consumers from the "cradle to the grave".

At present, most countries in the world, nearly all hospitals, aged care, community care and primary care settings independently maintain address books of local clinicians. These are used daily by doctors, nurses, and allied health professionals to aid the transfer and management of care. They range from simple lists to relatively sophisticated databases separate to or embedded within other systems. Few of these, however, are linked to a capacity for eHealth communication.

In 2010 Australia was no different from any other country. There were directories (databases) operating on a State/Territory basis, including the Victorian Human Services Directory (HSD), ${ }^{2}$ the South Australian Health Provider Registry, ${ }^{3}$ and the Tasmanian eHealth Directory. ${ }^{4}$ There are also active commercial directory providers (e.g., operated by secure messaging providers)' directories provided and managed by various organisations mainly on behalf of their members (general practice, physiotherapy, specialists, etc.), as well as separate databases supporting some health call centres activities.

\title{
Identifying the Need
}

This plethora of directories frustrated health service providers and contributed to problems in the uptake of e-health. They are often out of date or inaccurate; most cannot sustain electronic communications information or link to health identity 
(accreditation) services; the consent and management regimes are highly variable; maintenance costs are duplicated, and health service providers do not want to respond to a myriad of requests to insert and maintain their information into the various directories.

Service and provider information must be available quickly, easily, accurately, and reliably alongside of emerging identification, authentication, and messaging regimes if we are to use electronic communications effectively to support health services.

For example, when a GP or hospital-based doctor is planning further care for a patient with diabetes and renal dysfunction, they need to be able to:

- Access high quality information about various service providers in the patient's town or suburb

- Find a podiatrist, physiotherapist, dietician, pharmacist, etc.

- Assure themselves of the identity, provider status, address, etc. of those providers

- Access electronic address information easily available to refer the patient for further care.

\section{The Victorian Human Services Directory}

The Victorian Human Services Directory fulfils all the above functions as a repository of human and health services data, including service and practitioner details; contact details such as opening hours, location, national health identifiers for both organisations and providers; geo-coded service locations; and more.

Because of its success, the Australian Capital Territory (ACT $)^{\underline{5}}$ started to use it for their health consumers and organisations, followed by the Northern Territory (NT) as a Directory to hold electronic identifiers for secure messaging between all health and human services. This has further evolved into the National Health Services Directory (NHSD), ${ }_{2}^{1}$ which is now used by all state, territory, and federal governments, as well as the private sector.

This service is now run by HealthDirect Australia 1 on behalf of all stakeholders, including the federal government, states, and territories, public health care systems, 
national private healthcare, and pathology organizations, and consumers. For Australia, a population of 24 million people, it is the "Single Source of Truth" (stored in the Cloud) for health/human services and practitioner data, and it is the cornerstone for many national e-health initiatives, including:

- Covers the breadth and depth of Human and Health Services across Australia (Yellow pages)

- Is the single 'source of truth' for E-Health from the "Cloud" (Amazon Web Services)

- Handles over 7 million transactions/month (and growing as more national and state e-health initiatives start to use the national messaging facilities)

The NHSD is now the:

- National Services Directory (355,000+ Services)

- National Provider Directory (300,000+ accredited Health Practitioners)

- National Disability Insurance Scheme Directory (NDIS)

- National Telehealth Directory

- The "Foundation block" for the National My Health Record (Electronic Health Record)

And stores national health identifiers and secure messaging:

- Health Provider Identifiers: Individual (HPI-Is)

- Health Provider Identifiers: Organizational (HPI-Os)

- Secure Messaging EndPointer Location Service (ELS)

It also underpins many federal, state and local health initiatives such as the "National Nurse on Call" and the "GP after Hours" programs. ${ }^{7}$

The NHSD is a shared piece of national infrastructure and allows stakeholders to have varying degrees of control. Making the NHSD infrastructure ubiquitous has built a community of positive support because of its utility and ease of availability. The NHSD is accessible via websites, mobile apps, and application program interfaces (APIs), integrated into an increasing range of software products (Figure 1). 


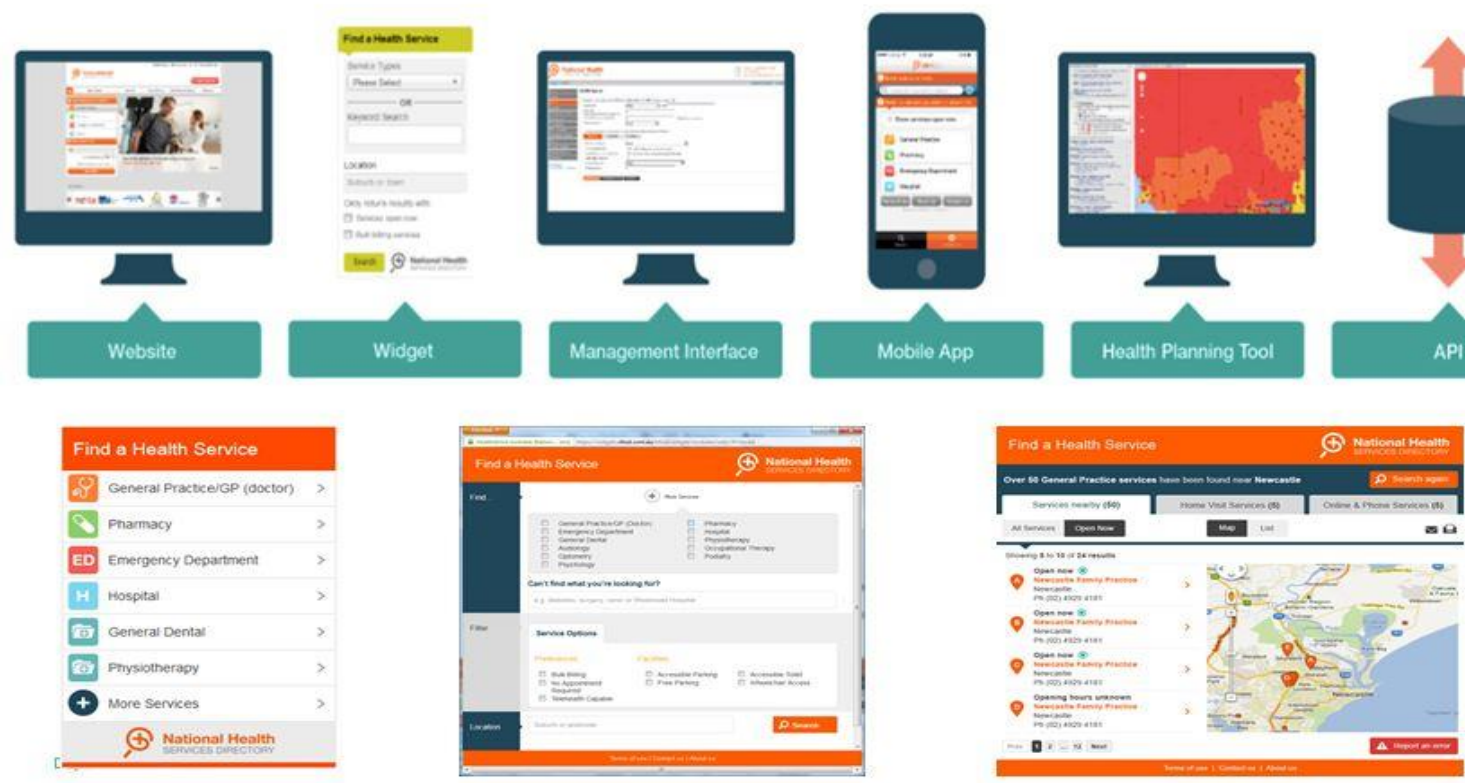

Figure 1. Accessibility to the NHSD allows stakeholders to have varying degrees of control.

With increasing demands on global health services, we urgently need to shift from primary and acute care to include "social care" (or community care), which has been a missing link in the context of "Cradle to the Grave" healthcare, so we can build healthy communities through knowledge-based environmental preventative strategies and sustainable active living principles. This can be done here and now by making data readily available in a more effective context to policy makers, health planners and researchers

\section{The National Healthmap Data Platform}

An example of a software product integrating the NHSD is the National Healthmap data platform. ${ }^{8}$ [Ed. Note: At this website, continue as a guest to view the maps.] This platform aims to help overcome the "islands of data" held across the health sector by combining the NHSD with a range of relevant health data sets, including census demographics, disease prevalence, and health outcomes.

The Healthmap demonstrates how the NHSD can be extended from its primary role as a foundation for national E-Health initiatives to a health data tool supporting policy 
makers, health planners, and researchers in their broader roles of improving population health outcomes through evidence based decision making (Figure 2). ${ }^{8}$

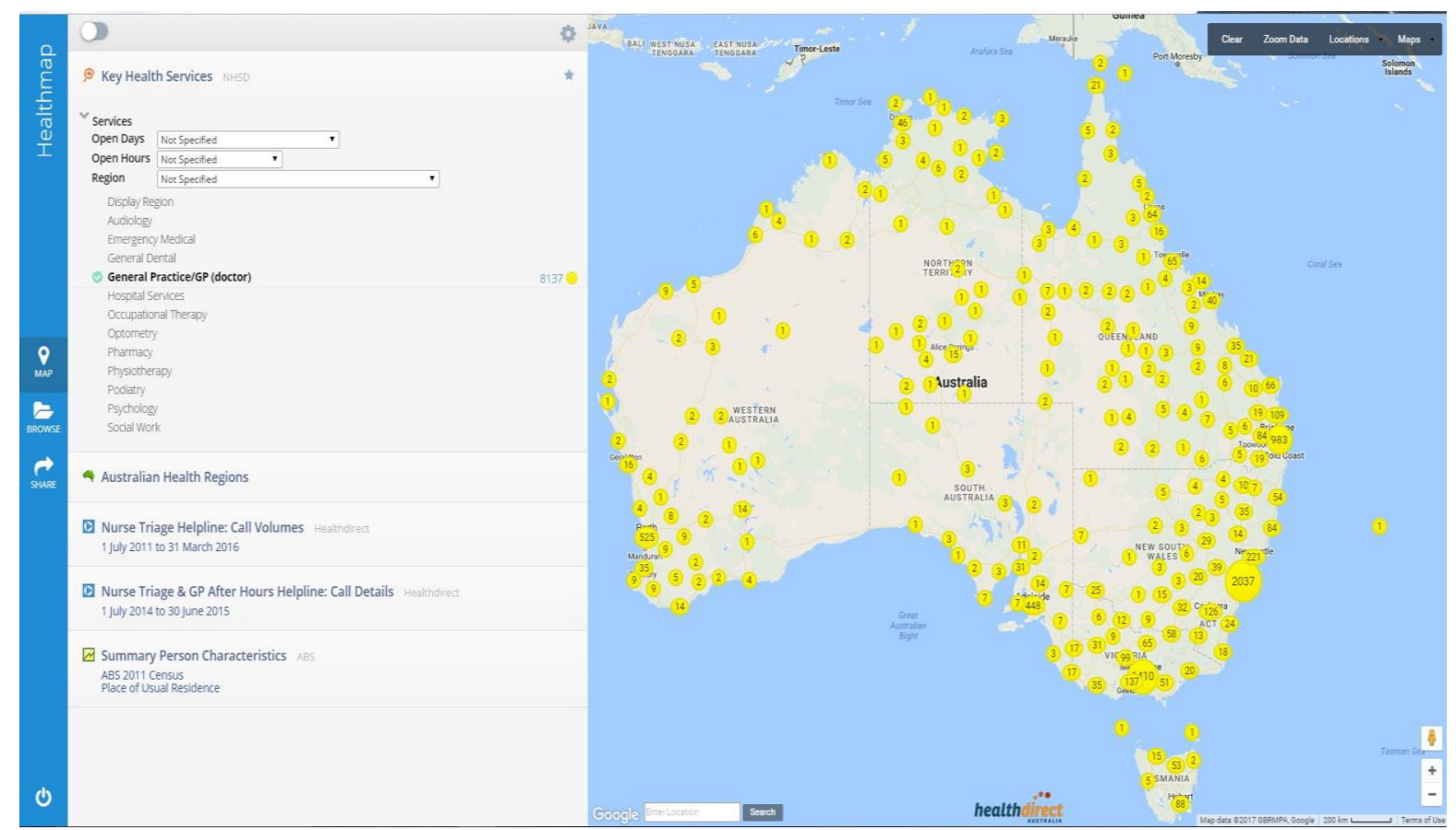

Figure 2. Physical location of GP's across Australia (which can be filtered by opening day, hours and region).

Visualization of data is extremely effective in bringing complex datasets to be together to convey information in a simple Geo-Spatial (Google Maps) format. The National Healthmap uses data from the NHSD, from which we can introduce a wide range of national datasets (e.g., census) and local health datasets to support a greater focus on evidence based planning and decision making. ${ }^{8}$ 
Page 6 of 9

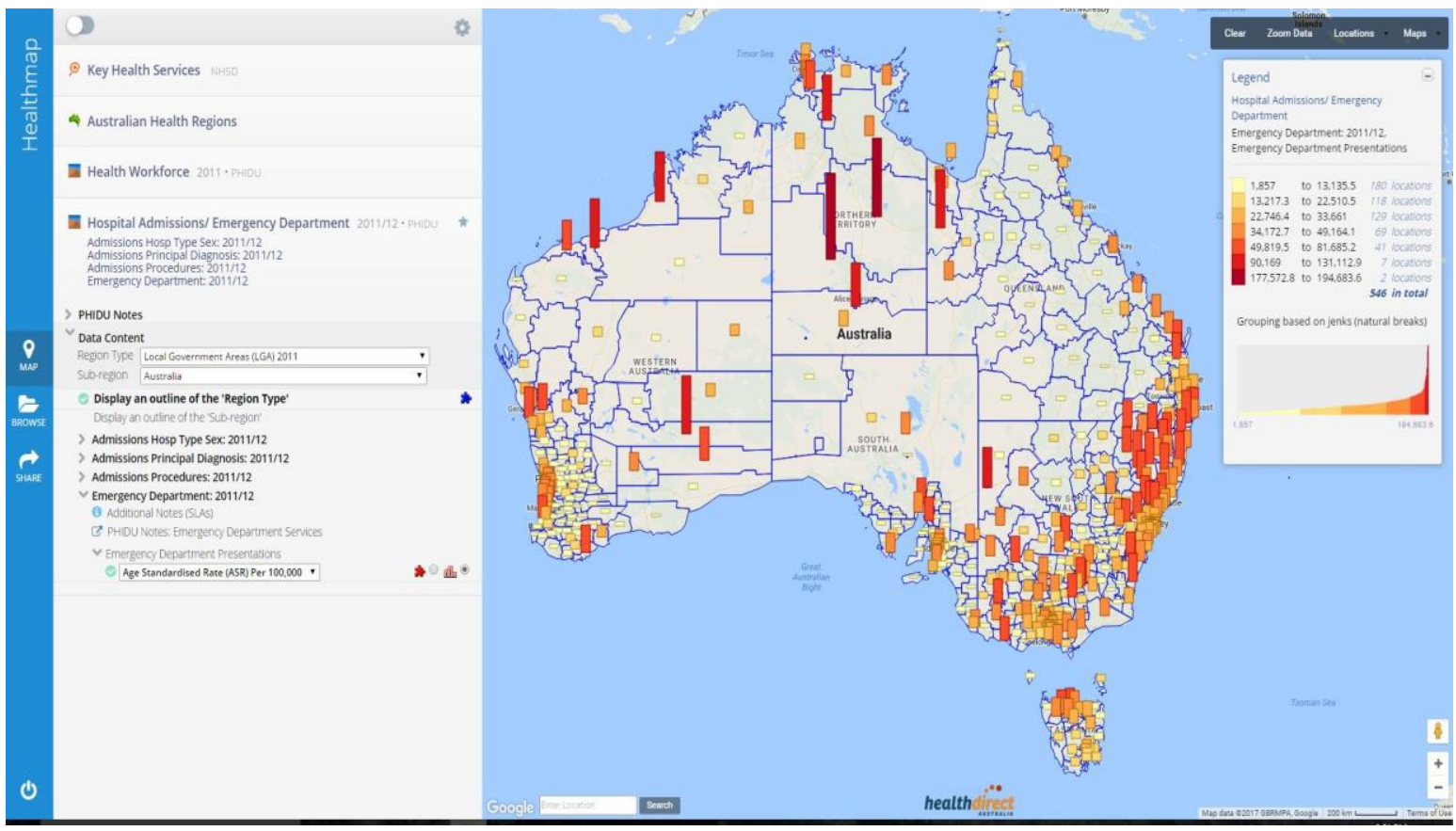

Figure 3. Emergency Department presentations.

Now that key service information can be sourced (from an authoritative resource), with greater focus on data governance rather than fragmented silos, data quality issues are reduced and we are opening more data possibilities to the greater community as it allows greater/more widespread use of data (Figure 4).

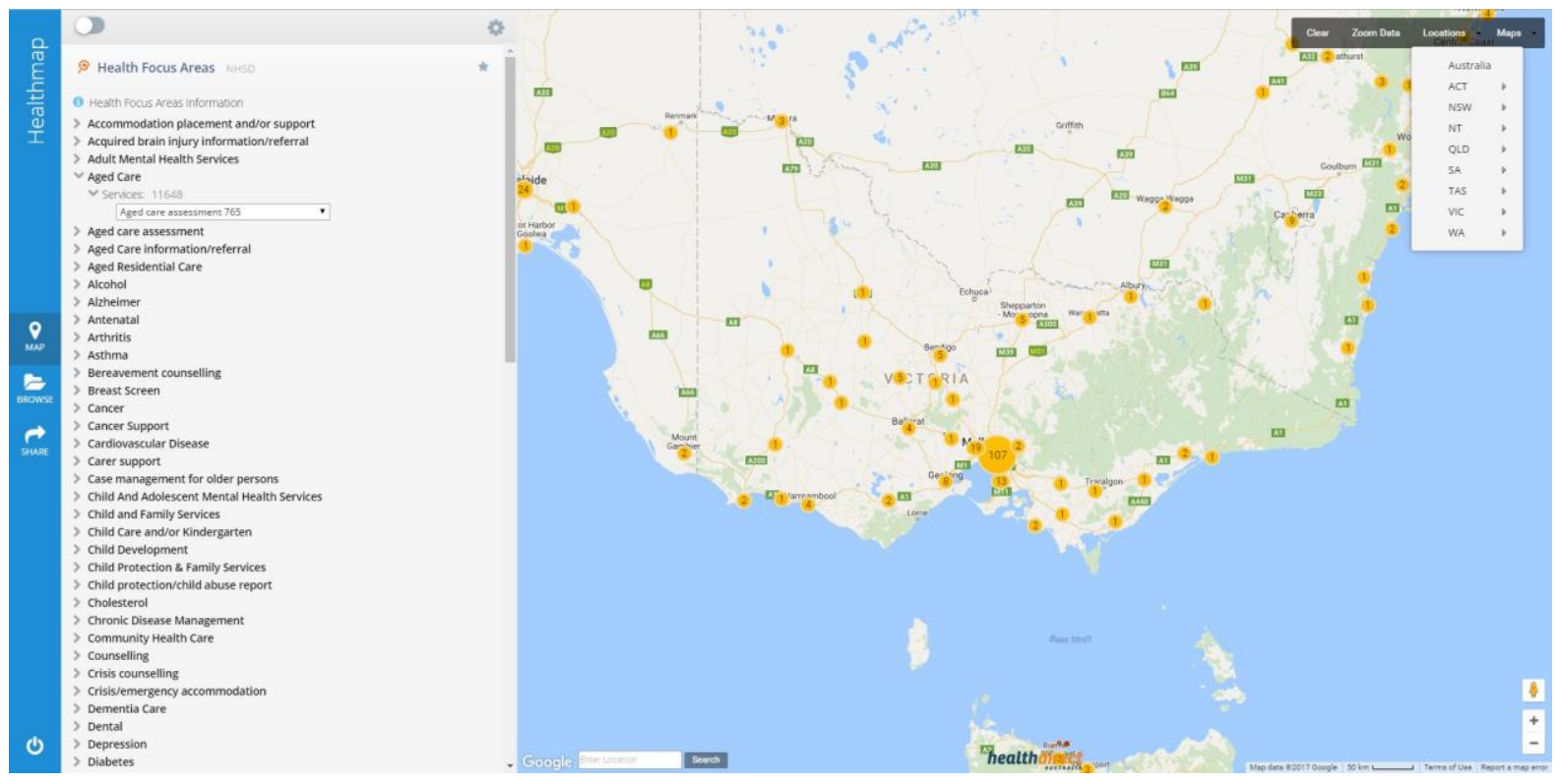


Figure 4. Service data can now be viewed by "Health Focus Areas" for example by cancer, aged care, etc., or categories or by programs by organisation" such as ATAPS (Access to Allied Psychological Services Program).

Other examples of the Healthmap include:

- General Medical Practitioners Rate per 100,000 people

- Avoidable mortality with Geographic Barcharts and Confidence Intervals

- Emergency medical Services: $100 \mathrm{~km}$ catchment radius

- Health Service Proximity of Influence regions for Remote Australia

- Districts of Workforce Shortage Storyboard

\section{Conclusions}

The NHSD can be replicated anywhere around the world. For example, National Human Services Directories linked together across the European Union to provide health consumers, health planners, research groups with a significant database of health and human services.

This could empower citizens when they travel. For example, they can see where Doctor (general practitioner) services are available after hours on the user's smartphone, an excellent example of providing the right data at the right time at the right place.

Barriers such as cost, technology, and data quality are common ones that have arisen. However, barriers are more readily overcome by demonstrating what is possible with the vast knowledge of health data coming from the "Cloud", and how effective it can be in health planning, evidence-based policy making, and empowering health consumers. Data quality is improved as we now have national data standards.

The National Health Services Directory (NHSD) acts as a catalyst for e-health delivering greater accessibility to relevant health sector data, provides a wealth of information resources to the health sector and consumers. 


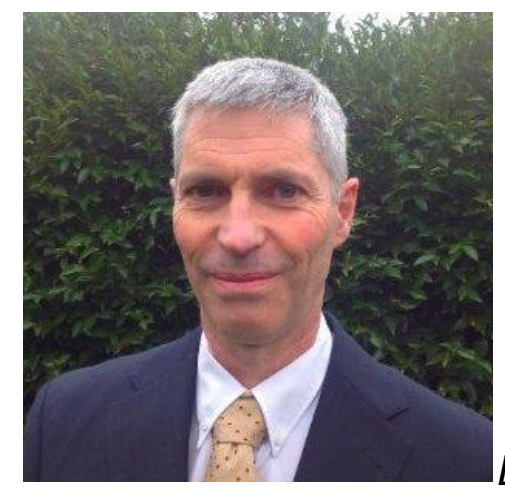

Laurie Hawkins is an passionate "Advocate" for the

National Health Services Directory (NHSD) and the National HealthMap which are used in Australia, He is credited with the significant achievement of gaining support from all States/Territories and the Federal government for the creation of a National Health Services Directory (NHSD) based on the Victorian Human Services Directory which he Project Managed. The NHSD became operational in July 2012, and is a "Cornerstone" on National E-Health Infrastructure, with over 7 million transactions a month

The National Healthmap evolved out of the "Arthritismap" which was created by Arthritis Victoria in Australia. The tool has unique functionality such as Planning Circles, Geographic Bar Charts, Confidence Indicators, Relative Measures, etc. and the website won the prestigious Don Walker Award - Access at the 2012 Health Informatics Conference (HIC) in August 2012.

\section{References}

1. National Health Services Directory. URL: http://www.nhsd.com.au/what-isnhsd. Accessed 2/27/17.

2. Human Services Directory. Welcome to the Human Services Directory. State Government of Victoria, Australia, Department of Human Services. URL: http://www.humanservicesdirectory.vic.gov.au/Home.aspx. Accessed 2/27/17.

3. Australian Health Practitioner Regulation Agency. Register of Practitioners. URL: http://www.ahpra.gov.au/registration/registers-of-practitioners.aspx. Accessed 2/27/17.

4. Primary Health Tasmania. Tasmanian Health Directory. URL: http://www.primaryhealthtas.com.au/find-a-provider. Accessed: 2/27/17. 
5. ACT Health find-a-health service. URL:

http://findahealthservice.act.gov.au/c/fahs?a=da\&did=10000882. Accessed 2/27/17.

6. URL: https://www.healthdirect.gov.au. Accessed 2/17/17.

7. Healthdirect. After Hours GP Hotline. URL:

https://www.healthdirect.gov.au/after-hours-gp-helpline. Accessed 2/27/17.

8. The National Healthmap Data Platform. URL: https://healthmap.com.au. Accessed 2/27/17.

\section{Category: Opinion}

\section{Tags:}

Australia, how telehealth enhances the doctor patient relationship, National Health Services Directory, National Healthmap, NHSD, telehealth and telemedicine, telemedicine process improvement, telemedicine program implementation, telemedicine remote health, what is telemedicine and how does it work 